\title{
Cardiofaciocutaneous syndrome - a longitudinal study of a case over 33 years: case report and review of the literature
}

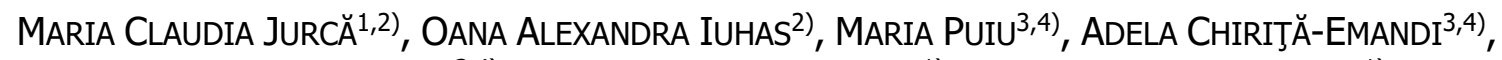

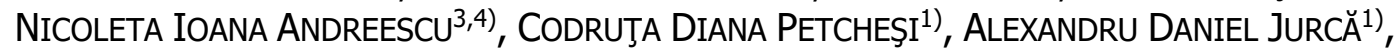 \\ IOAN MAGYAR ${ }^{1)}$, SÂNZIANA IULIA JURCĂ ${ }^{5)}$, KINGA KOZMA ${ }^{1,2)}$, EMILIA MARIA SEVERIN ${ }^{6}$ ), \\ MARIUS BEMBEA ${ }^{2)}$
}

1) Department of Preclinical Disciplines, Faculty of Medicine and Pharmacy, University of Oradea, Romania

2) Regional Center of Medical Genetics Bihor, Dr. Gavril Curteanu Municipal Clinical Hospital, Oradea, Romania (part of ERN ITHACA)

3) Department of Microscopic Morphology - Genetics, Center of Genomic Medicine, Victor Babeş University of Medicine and Pharmacy, Timişoara, Romania

4) Regional Center of Medical Genetics Timiş, Louis Turcanu Clinical Emergency Hospital for Children, Timişoara, Romania (part of ERN ITHACA)

5) Student, Faculty of Medicine and Pharmacy, University of Oradea, Romania

${ }^{6)}$ Department of Genetics, Carol Davila University of Medicine and Pharmacy, Bucharest, Romania

\begin{abstract}
Cardiofaciocutaneous (CFC) syndrome [Online Mendelian Inheritance in Man (OMIM) \#115150] is characterized by craniofacial dysmorphism, heart malformation, ectodermal abnormalities, neuromotor delay and intellectual disability. It is not a frequent disease, about 300 cases have been reported in the medical literature. We describe the case of a 34-year-old patient presenting with CFC syndrome phenotype, monitored since the age of $11 / 2$ years. Clinical findings included craniofacial dysmorphism, development delay, heart malformation and severe intellectual disability. The evolution was with progressive intellectual disability, hypogonadism, hypertrophic cardiomyopathy, wrinkled palms and soles. Molecular analysis showed a heterozygous variant in the B-Raf proto-oncogene, serine/threonine kinase (BRAF) gene (7q34): NM_001354609.2:C.1502A>G, with pathogenic significance. We report this case, observed along a period of 33 years, for illustration of clinical evolutive particularities, and for difficulties in establishing the positive diagnosis.
\end{abstract}

Keywords: cardiofaciocutaneous syndrome, craniofacial dysmorphism, intellectual disability, hypertrophic cardiomyopathy.

\section{a Introduction}

Cardiofaciocutaneous (CFC) syndrome is a very rare syndrome characterized by craniofacial dysmorphism, heart and skin anomalies, developmental delay, and intellectual disability. The syndrome was described by Reynolds et al., in 1986 [1, 2]. It is an autosomal dominant trait but most of the cases are due to de novo mutations. CFC is included in the large group of RASopathies. The latter term comprises a group of diseases caused by the appearance of germline mutations in genes encoding rat sarcoma (RAS)/ mitogen-activated protein kinase (MAPK) signaling pathway [3]. This group includes the following syndromes: von Recklinghausen's disease, male Turner syndrome [Noonan syndrome (NS)], LEOPARD syndrome, Costello syndrome (CS), capillary malformation-arteriovenous malformation syndrome, CFC syndrome, neurofibromatosis 1 (NF1)-like syndrome [4]. All these syndromes present few features in common: facial dysmorphism, heart malformations, mental retardation, teaching problems, skin conditions, undescended testicle, high risk for malignant tumors. Thus, from this point of view, it is difficult to make the differential diagnosis only based on the clinical aspect, the molecular being mandatory.

\section{Aim}

The purpose of this article was to better understand the genotype-phenotype correlation of this very rare genetic disorder.

\section{ㅁ Case presentation}

The probandus, O.A. male, was in evidence at Regional Center of Medical Genetics, Bihor County, Romania, from the age of 18 months, for development and language delay, neuromotor retardation with delayed stands and walk. The pregnancy was normal. The boy was born at term, spontaneous vaginal delivery, with the birth weight of $3800 \mathrm{~g}$, and a good adaptation at extrauterine life. His parents were young, healthy, non-consanguineous marriage.

\section{Clinical examination}

Clinical examination revealed:

- Delayed physical, cognitive, emotional and linguistic development;

- Craniofacial dysmorphism: macrocephaly, high forehead, bitemporal narrowing, thin, brittle, sparse hair, hypoplastic supraorbital ridges, large and depressed nasal bridge,

This is an open-access article distributed under the terms of a Creative Commons Attribution-NonCommercial-ShareAlike 4.0 International Public License, which permits unrestricted use, adaptation, distribution and reproduction in any medium, non-commercially, provided the new creations are licensed under identical terms as the original work and the original work is properly cited. 
hypertelorism, very sparse eyebrows and eyelashes, large and posterior rotated ears, thickened helices, short nose, long philtrum, microretrognathia, high arched palate, anomalies of dental eruption, short neck, bilateral cryptorchidism (Figure 1);

- Clinical signs newly highlighted throughout our observation: short stature, prominent forehead, ptosis, strabismus, webbed neck, curly hair, dystrophic nails, palmar and plantar hyperkeratosis, hypertrophic cardiomyopathy, compulsive, hetero-aggressive behavior (Figures 2-4).

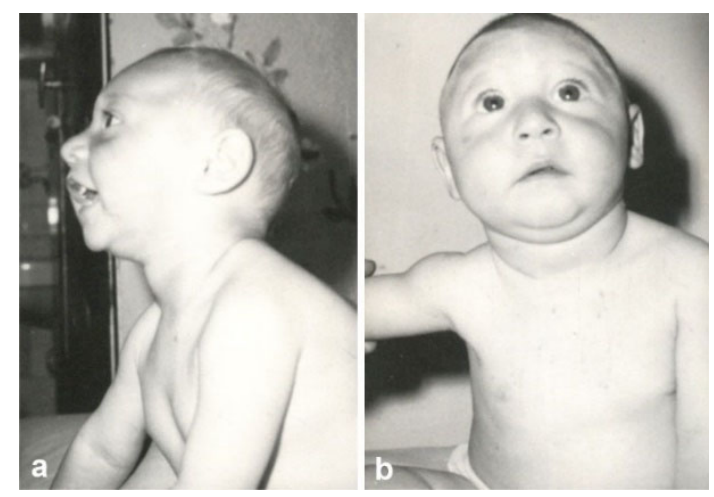

Figure 1 - ( $a$ and $b)$ The patient at first presentation (age 18 months).
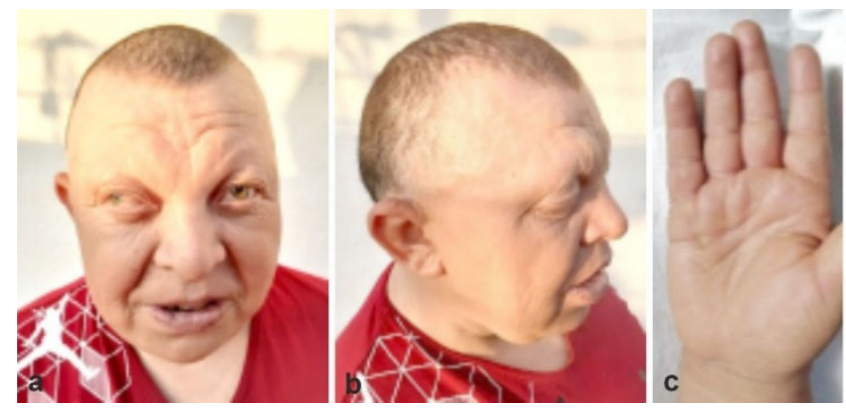

\section{Genetic analysis}

\section{Molecular diagnosis}

Next Generation Sequencing analysis was performed, at the age of 32 years. Genomic deoxyribonucleic acid (DNA) isolation was performed according to the protocol provided by the manufacturer, by using the MagCore ${ }^{\circledR}$ Automated Nucleic Acid Extractor and the MagCore ${ }^{\circledR}$ Genomic DNA Whole Blood Kit (RBC Bioscience). DNA concentrations and DNA purity were evaluated by using Qubit ${ }^{\circledR}$ double-stranded DNA (dsDNA) high sensitivity (HS) Assay Kit (Invitrogen) according to the instructions provided by the manufacturer. Amplicon sequencing libraries were prepared from $50 \mathrm{ng}$ of DNA per sample according to the TruSight ${ }^{\circledR}$ Cardio protocol (Illumina Inc., San Diego, CA, USA). The genomic DNA was fragmented, then the coding sequencing were amplified, and libraries were generated using Illumina TruSight ${ }^{\mathbb{R}}$ Cardio Sequencing panel (174 genes). The pooled libraries were sequenced on a microflow cell with $\mathrm{V} 3$ chemistry on a MiSeq instrument (Illumina Inc., San Diego, CA, USA). Variants were interpreted according to American College of Medical Genetics and Genomics (ACMG) Guide. A heterozygous variant of B-Raf proto-oncogene, serine/threonine kinase (BRAF) gene [NM_001354609.2):c.1502A>G,p.Glu501Gly,

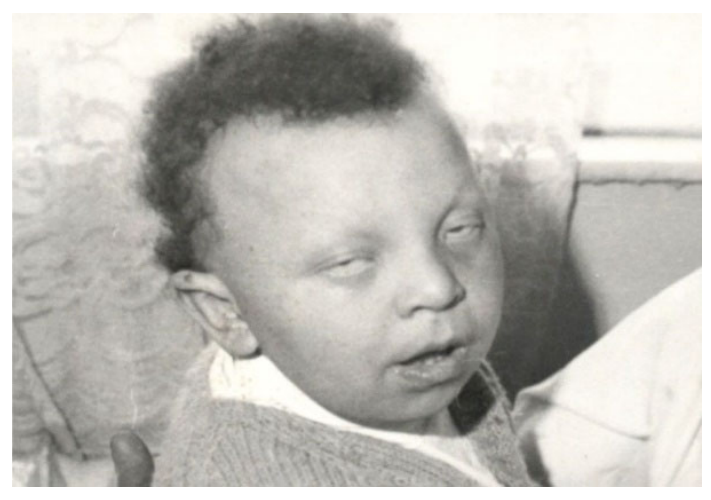

Figure 2 - The patient at the age of seven years.
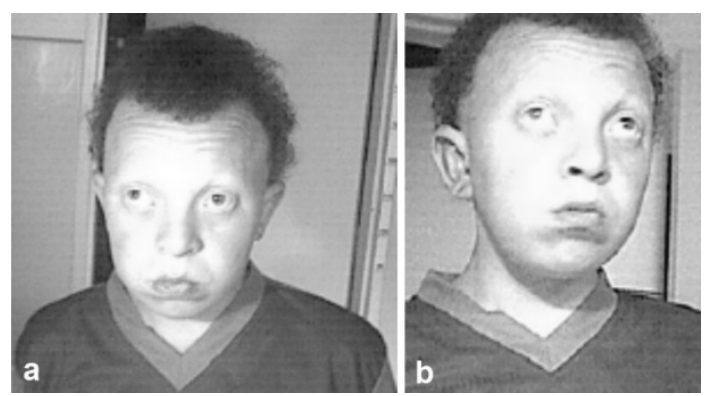

Figure 3 - ( $(a$ and $b)$ The patient at the age of 21 years.

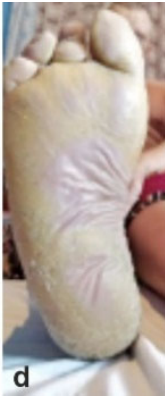

Figure 4 - The patient at the age of 34 years: (a and b) Craniofacial dysmorphism; (c and d) Palmoplantar hyperkeratosis.

rs180177039 (chromosome 7q34)] was identified and classified as pathogenic. The variant is not present in population databases and was reported in other patients with CFC syndrome.

\section{Laboratory investigations}

Hematological, biochemical and endocrinology work-up were normal.

Lysosomal enzymes at the age of 30 years were normal (alpha-L-iduronidase, iduronate-2-sulfatase, arylsulfatase B and beta-galactosidase).

Imagistic investigations: $X$-ray: the bone age (wrist radiography) at the age of 16 years was delayed with two years, bilateral brachymetacarpia of the first metacarpal. Abdominal ultrasound showed mild hepatomegaly, ptosis of the right kidney and the right renal cyst.

\section{Interdisciplinary checkups}

Ophthalmological exam revealed alternate strabismus. Cardiological exam showed moderate mitral, aortic and tricuspid insufficiency and hypertrophic cardiomyopathy. Gynecological exam showed ectopic testis. Neurological exam revealed neuromotor retardation. Psychological exam revealed a severe intellectual disability, intelligence quotient (IQ) $<25$, behavioral problems, aggression. 


\section{Discussions}

CFC syndrome is an autosomal dominant syndrome, with complete penetrance [5]. Most affected individuals reported to date have had a de novo pathogenic variant. It was first described in 1986 by Reynolds et al. [1] and Baraitser \& Patton [2]. It is a very rare syndrome; around 300 cases are reported in literature. The real incidence is still unknown, in Japan the prevalence is estimated at $1: 810000[6,7]$. The clinical diagnosis is not enough, the molecular genetic testing is mandatory. Four genes are involved in CFC syndrome: $B R A F$ gene (7q34) present in majority (75\%) of the cases, mitogen-activated protein kinase kinase 1 (MAP2K1 or $M E K)$ gene (15q22.1-q22.33) and mitogen-activated protein kinase kinase 2 (MAP2K2) gene (19p13.3), both are present in $25 \%$ of the cases, and the last, Kirsten rat sarcoma viral oncogene homolog $(K R A S)$ gene $(12 \mathrm{p} 12.1)$ present in less than $2 \%$ of the cases. All these genes are codifying for proteins of the RAS/MAPK signaling pathway. The RAS/MAPK pathway plays an important role in cell differentiation, proliferation, migration, and apoptosis. Our case presented a heterozygous variant $N M$ 001354609.2:1502A>G of the BRAF gene [8]. The $B R \overline{A F}$ gene codify a serine/threonine-protein kinase, B-Raf protein, important in the transduction of chemical signals from the cell membrane (outside) to the cell nucleus (inside) and it is important in the postsynaptic responses of hippocampal neurons [9].

\section{Diagnosis}

The diagnosis is made based on clinical aspects: craniofacial dysmorphism, developmental delay, neuromotor delay, intellectual disability, ectodermal abnormalities, heart malformation and hypertrophic cardiomyopathy, cryptorchidism. Our patient presented all these features (Table 1) characteristics of RASopathies and, as particular signs and symptoms, present elongated filter, microretrognathism, absence of heart malformation and an important aggressive behavior (he manifests, periodically, physical and emotional abuse on the family and other known and unknown persons, from verbal abuse to physical abuse). What is very particular to our case is the change, over time, of the phenotype. From Table 1, it can be seen that some features are present from infancy, others appear in childhood or adolescence, while others manifest only in adulthood. At the same time, it can be observed that some features change over time either by their accentuation (short stature, mental retardation, cranial dysmorphism, skin changes, and aggressive behavior) or by their regression (bitemporal narrowing, depressed nasal bridge, sparse hair, ectopia testis). These phenotypic changes that occur during evolution create diagnostic difficulties. The case presented by us, evaluated periodically over more than 30 years, was evaluated for multiple differential diagnoses, such as mucopolysaccharidosis, Legius syndrome [Online Mendelian Inheritance in Man (OMIM) \#611431], CS (OMIM \#218040), NS (OMIM\#163950), CFC1 syndrome, the final diagnosis being defined by the molecular test.

\section{Differential diagnosis}

The differential diagnosis was made with the other syndromes which are included in RASopaties pathway, in special with NS and CS. Table 2 shows the common signs and symptoms of the three syndromes.
Table 1 - The evolution of phenotype over 34 years of life

\begin{tabular}{|c|c|c|c|c|}
\hline Signs and symptoms & $\begin{array}{c}18 \\
\text { months }\end{array}$ & $\begin{array}{c}7 \\
\text { years }\end{array}$ & $\begin{array}{c}21 \\
\text { years }\end{array}$ & $\begin{array}{c}34 \\
\text { years }\end{array}$ \\
\hline Short stature & - & + & ++ & ++ \\
\hline Developmental delay & + & ++ & ++ & ++ \\
\hline Intellectual disability & + & ++ & +++ & +++ \\
\hline Macrocephaly & + & +++ & +++ & +++ \\
\hline Height forehead & + & +++ & +++ & +++ \\
\hline Prominent forehead & - & +++ & +++ & +++ \\
\hline Bitemporal narrowing & ++ & + & + & + \\
\hline Hypoplastic supraorbital ridges & + & + & + & + \\
\hline Large and posteriorly rotated ears & + & + & + & + \\
\hline Thickened helices & + & ++ & ++ & ++ \\
\hline Sparse eyebrows and eyelashes & + & ++ & ++ & ++ \\
\hline Hypertelorism & + & ++ & ++ & ++ \\
\hline Ptosis & - & + & + & + \\
\hline Strabismus & - & + & + & + \\
\hline $\begin{array}{l}\text { Large and depressed nasal } \\
\text { bridge }\end{array}$ & ++ & + & + & + \\
\hline Short nose & + & + & + & + \\
\hline Long philtrum & + & + & + & + \\
\hline Microretrognathia & + & ++ & ++ & ++ \\
\hline High arched palate & + & + & + & + \\
\hline Webbed neck & - & + & ++ & ++ \\
\hline Short neck & + & + & ++ & ++ \\
\hline Palmar and plantar hyperkeratosis & - & - & + & ++ \\
\hline Dystrophic nails & - & + & + & + \\
\hline Curly hair & - & + & ++ & ++ \\
\hline Sparse hair & ++ & + & + & + \\
\hline Hypertrophic cardiomyopathy & - & - & - & + \\
\hline Bilateral cryptorchidism & + & + & - & - \\
\hline $\begin{array}{l}\text { Compulsive, hetero-aggressive } \\
\text { behavior }\end{array}$ & - & + & ++ & + \\
\hline
\end{tabular}

Characteristic features in NS are short stature, short, wide, neck, low posterior hairline, café-au-lait spots, aortic or pulmonary stenosis, coagulation disorders. In approximately $50 \%$ of patients there have been identified mutations in protein tyrosine phosphatase non-receptor type 11 (PTPN11) gene [10-12]. Characteristic features in CS are short stature, failure to thrive, coarse facies, cardiac malformations, mental retardation, deep creases on the palms and soles, elbow joint limitation and predisposition to solid tumors (neuroblastoma) [13, 14]. In 2005, Aoki et al. identified a pathogenic variant in Harvey rat sarcoma viral oncogene homolog $(H R A S)$ gene in most patients with CS [15].

There are currently not many studies regarding the genotype-phenotype correlation. Pierpont et al. [4] developed in 2014 a Guideline for genetic testing strategy for CFC syndrome. An important observation is the presence of pulmonic stenosis in $50 \%$ of persons with CFC which have mutation in $B R A F$ gene; only $36 \%$ of persons have $M E K$ gene mutation. It was found that $B R A F$ mutations are frequently correlated with heart damage (hypertrophic cardiomyopathy, interatrial communication), intellectual disability, eating problems [16-18]. In our report, the patient developed hypertrophic cardiomyopathy after the age of 20 years. He also presented severe intellectual disability. Although dermatological and renal changes are more common in patients with mutations in $M E K$ gene, our patient presents palmoplantar hyperkeratosis and right renal cyst [19-21]. 
Table 2 - Clinical signs and symptoms in CFC1 syndrome, Noonan syndrome, Costello syndrome, Legius syndrome and in our case

\begin{tabular}{|c|c|c|c|c|c|}
\hline Clinical signs and symptoms & $\begin{array}{c}\text { CFC1 } \\
\text { syndrome }\end{array}$ & $\begin{array}{c}\text { Noonan } \\
\text { syndrome }\end{array}$ & $\begin{array}{c}\text { Costello } \\
\text { syndrome }\end{array}$ & $\begin{array}{c}\text { Legius } \\
\text { syndrome }\end{array}$ & $\begin{array}{l}\text { Our } \\
\text { case }\end{array}$ \\
\hline Onset 1-2 years & + & + & + & & $\sqrt{ }$ \\
\hline Failure to thrive & + & & + & & \\
\hline Short stature & + & & + & & $\sqrt{ }$ \\
\hline \multicolumn{6}{|l|}{ Craniofacial dysmorphism } \\
\hline Macrocephaly & + & & + & + & $\sqrt{ }$ \\
\hline Prominent forehead & + & & & & $\sqrt{ }$ \\
\hline Bitemporal narrowing & + & & & & $\sqrt{ }$ \\
\hline Triangular face & & + & & + & \\
\hline Coarse facies & & & + & & $\sqrt{ }$ \\
\hline Hypoplastic supraorbital ridges & + & & & & $\sqrt{ }$ \\
\hline Posteriorly rotated ears & + & + & + & & $\sqrt{ }$ \\
\hline Thickened helices & + & & + & & $\sqrt{ }$ \\
\hline Preauricular pits & + & & & & \\
\hline Hearing loss & & + & & & \\
\hline Hypertelorism & + & + & + & + & $\sqrt{ }$ \\
\hline Downslanting palpebral fissures & + & + & + & + & \\
\hline Epicanthal folds & + & + & + & + & \\
\hline Ptosis & + & + & + & + & $\sqrt{ }$ \\
\hline Nystagmus & + & & & & \\
\hline Strabismus & + & & + & & $\sqrt{ }$ \\
\hline Myopia & & + & & & \\
\hline Depressed nasal bridge & + & & + & & $\sqrt{ }$ \\
\hline Anteverted nares & + & & + & & \\
\hline Deeply, long, philtrum & & + & & + & $\sqrt{ }$ \\
\hline Thick lips & & & + & & $\sqrt{ }$ \\
\hline High arched palate & + & + & + & + & $\sqrt{ }$ \\
\hline Dental anomalies & & + & + & & $\sqrt{ }$ \\
\hline Microretrognathia & & + & + & + & $\sqrt{ }$ \\
\hline \multicolumn{6}{|l|}{ Neck and thorax } \\
\hline Webbed, short neck & + & + & + & & $\sqrt{ }$ \\
\hline Deformed chest & & + & + & & \\
\hline Pectus carinatum / pectus excavatum & & + & + & & \\
\hline \multicolumn{6}{|l|}{ Heart problems } \\
\hline Congenital heart malformation & + & + & + & & \\
\hline Hypertrophic cardiomyopathy & + & + & + & & $\sqrt{ }$ \\
\hline \multicolumn{6}{|l|}{ Cutaneous } \\
\hline Deep palmar and plantar creases & + & & + & & $\sqrt{ }$ \\
\hline Café-au-lait spots & & & & + & \\
\hline Ichthyosis, hyperkeratosis & + & & + & & $\sqrt{ }$ \\
\hline Cutis laxa, dark skin, acanthosis, papillomas & & & + & & \\
\hline Sparse, curly hair, sparse eyebrows & + & & + & & $\sqrt{ }$ \\
\hline Low posterior hairline & & + & & + & \\
\hline \multicolumn{6}{|l|}{ Skeletal } \\
\hline Scoliosis / other vertebral anomalies & + & & & & $\sqrt{ }$ \\
\hline Limbs' abnormalities & + & & + & & \\
\hline \multicolumn{6}{|l|}{ Neurological } \\
\hline Developmental delay & + & & + & & $\sqrt{ }$ \\
\hline Intellectual disability & + & + & + & $+/-$ & $\sqrt{ }$ \\
\hline Hypotonia & + & & & & \\
\hline \multicolumn{6}{|l|}{ Another anomalies } \\
\hline Cryptorchidism & & + & & & $\sqrt{ }$ \\
\hline Lymphedema & & + & & & \\
\hline Tracheobronchomalacia & & & + & & \\
\hline Lung disorders, respiratory failure & & & + & & \\
\hline
\end{tabular}




\section{Management of CFC syndrome}

There is not specific treatment in CFC syndrome. A multidisciplinary team must be gathered for managing the main issues that are presents in this pathology: cardiac, digestive, dermatological, renal problems; also, the neurological problem and psychomotor development must be monitored periodically.

\section{Genetic counselling}

$\mathrm{CFC}$ is an autosomal dominant trait with full penetrance. The recurrence risk for the child of an affected person is $50 \%$. Majority of cases presents de novo pathogenic variants. The prenatal diagnosis will be possible in situation in which the pathogenic variants $(B R A F, M A P 2 K 1, M A P 2 K 2$, or $K R A S$ genes) have been identified in an affected person from the family.

\section{ㅁ Conclusions}

The clinical appearance of CFC patients partially overlaps with that of patients with other syndromes of RAS/MAPK pathway, therefore, a right diagnosis is crucial for good monitoring and for a good and correct genetic counseling. The identification of the mutation is recommended for each patient with suggestive clinical signs, to establish the most accurate genotype-phenotype correlation. A multidisciplinary team is necessary both to the children and adults with CFC syndrome. As particularities of our case can be mentioned particular phenotypic traits that are not part of the usual picture of the disease; phenotypic changes that occur during multiannual clinical observation and that may induce changes in diagnostic interpretations.

\section{Conflict of interests}

The authors declare that they have no conflict of interests.

\section{Consent}

Written informed consent was obtained from the patient's parents for publication of this Case Report and any accompanying images. A copy of the written consent is available for review by the Editor-in-Chief of this Journal.

\section{References}

[1] Reynolds JF, Neri G, Herrmann JP, Blumberg B, Coldwell JG Miles PV, Opitz JM. New multiple congenital anomalies/ mental retardation syndrome with cardio-facio-cutaneous involvement - the CFC syndrome. Am J Med Genet, 1986, 25(3):413-427. https://doi.org/10.1002/ajmg.1320250303 PMID: 3789005

[2] Baraitser M, Patton MA. A Noonan-like short stature syndrome with sparse hair. J Med Genet, 1986, 23(2):161-164. https:// doi.org/10.1136/jmg.23.2.161 PMID: 3712393 PMCID: PMC 1049573

[3] Rodríguez F, Vallejos C, Bolanos-Garcia VM, Ponce D, Unanue N, Garay F, Cassorla F, Aracena M. Co-occurrence of Noonan and cardiofaciocutaneous syndrome features in a patient with KRAS variant. J Pediatr Genet, 2018, 7(4):158_ 163. https://doi.org/10.1055/s-0038-1653977 PMID: 30430033 PMCID: PMC6234039

[4] Pierpont MEM, Magoulas PL, Adi S, Kavamura MI, Neri G, Noonan J, Pierpont EI, Reinker K, Roberts AE, Shankar S, Sullivan J, Wolford M, Conger B, Cruz MS, BS, Rauen KA Cardio-facio-cutaneous syndrome: clinical features, diagnosis, and management guidelines. Pediatrics, 2014, 134(4):e1149- e1162. https://doi.org/10.1542/peds.2013-3189 PMID: 25180280 PMCID: PMC4179092

[5] Rauen KA, Tidyman WE, Estep AL, Sampath S, Peltier HM, Bale SJ, Lacassie Y. Molecular and functional analysis of a novel MEK2 mutation in cardio-facio-cutaneous syndrome: transmission through four generations. Am J Med Genet A, 2010, 152A(4):807-814. https://doi.org/10.1002/ajmg.a.33342 PMID: 20358587 PMCID: PMC4180666

[6] Rauen KA. The RASopathies. Annu Rev Genomics Hum Genet, 2013, 14:355-369. https://doi.org/10.1146/annurev-genom091212-153523 PMID: 23875798 PMCID: PMC4115674

[7] Abe Y, Aoki Y, Kuriyama S, Kawame H, Okamoto N, Kurosawa K, Ohashi H, Mizuno S, Ogata T, Kure S, Niihori T, Matsubara Y; Costello and CFC Syndrome Study Group in Japan. Prevalence and clinical features of Costello syndrome and cardio-faciocutaneous syndrome in Japan: findings from a nationwide epidemiological survey. Am J Med Genet A, 2012, 158A(5): 1083-1094. https://doi.org/10.1002/ajmg.a.35292 PMID: 22495831

[8] Ciara E, Pelc M, Jurkiewicz D, Kugaudo M, GieruszczakBiałek D, Skórka A, Posmyk R, Jakubiuk-Tomaszuk A, Cieślikowska A, Chrzanowska KH, Jezela-Stanek A, KrajewskaWalasek M. Is diagnosing cardio-facio-cutaneous (CFC) syndrome still a challenge? Delineation of the phenotype in 15 Polish patients with proven mutations, including novel mutations in the BRAF1 gene. Eur J Med Genet, 2015, 58(1):14-20. https://doi.org/10.1016/j.ejmg.2014.11.002 PMID: 25463315

[9] Stephens RM, Sithanandam G, Copeland TD, Kaplan DR, Rapp UR, Morrison D. 95-kilodalton B-Raf serine/threonine kinase: identification of the protein and its major autophosphorylation site. Mol Cell Biol, 1992, 12(9):3733-3742. https:// doi.org/10.1128/mcb.12.9.3733-3742.1992 PMID: 1508179 PMCID: PMC360233

[10] Pavithra S, Mallya H, Pai G. Cardiofaciocutaneous syndrome: a rare entity. Indian J Dermatol, 2012, 57(4):299-301. https:// doi.org/10.4103/0019-5154.97677 PMID: 22837569 PMCID: PMC3401850

[11] Neri G, Zollino M, Reynolds JF. The Noonan-CFC controversy. Am J Med Genet, 1991, 39(3):367-370. https://doi.org/10.1002/ ajmg.1320390323 PMID: 1867292

[12] Tartaglia M, Pennacchio LA, Zhao C, Yadav KK, Fodale V, Sarkozy A, Pandit B, Oishi K, Martinelli S, Schackwitz W, Ustaszewska A, Martin J, Bristow J, Carta C, Lepri F, Neri C, Vasta I, Gibson K, Curry CJ, Siguero JP, Digilio MC, Zampino G, Dallapiccola B, Bar-Sagi D, Gelb BD. Gain-of-function SOS1 mutations cause a distinctive form of Noonan syndrome. Nat Genet, 2007, 39(1):75-79. https://doi.org/10.1038/ng1939 PMID: 17143282

[13] Neri G, Kavamura MI, Zollino M, Opitz JM. CFC syndrome. Am J Med Genet A, 2003, 116A(4):410. https://doi.org/10.1002/ ajmg.a.10012 PMID: 12522802

[14] Roberts A, Allanson J, Jadico SK, Kavamura MI, Noonan J, Opitz JM, Young T, Neri G. The cardiofaciocutaneous syndrome. J Med Genet, 2006, 43(11):833-842. https://doi.org/10.1136/ jmg.2006.042796 PMID: 16825433 PMCID: PMC2563180

[15] Aoki Y, Niihori T, Kawame H, Kurosawa K, Ohashi H, Tanaka Y, Filocamo M, Kato K, Suzuki Y, Kure S, Matsubara Y. Germline mutations in HRAS protooncogene cause Costello syndrome. Nat Genet, 2005, 37(10):1038-1040. https://doi.org/10.1038/ ng1641 PMID: 16170316

[16] Jurca $C$, Bembea $M$, Pallag A, Mureşan M, Szilagyi A, Balmoş A, Pop O, Jurca A, Dobjanschi L. Pharmacotherapeutical considerations in the treatment and management of neonatal hyperammonaemia. Farmacia, 2018, 66(2):216222. https://farmaciajournal.com/issue-articles/pharmacothera peutical-considerations-in-the-treatment-and-management-ofneonatal-hyperammonaemia/

[17] Tidyman WE, Rauen KA. Noonan, Costello and cardio-faciocutaneous syndromes: dysregulation of the Ras-MAPK pathway. Expert Rev Mol Med, 2008, 10:e37. https://doi.org/10.1017/ S1462399408000902 PMID: 19063751

[18] Jurcă AD, Kozma K, loana M, Streaţă I, Petcheşi CD, Bembea M, Jurcă MC, Cuc EA, Vesa CM, Buhaş CL. Morphological and genetic abnormalities in a Jacobsen syndrome. Rom J Morphol Embryol, 2017, 58(4):1531-1534. PMID: 29556653

[19] Allanson JE, Annerén G, Aoki Y, Armour CM, Bondeson ML, Cave H, Gripp KW, Kerr B, Nystrom AM, Sol-Church K, 
Verloes A, Zenker M. Cardio-facio-cutaneous syndrome: does genotype predict phenotype? Am J Med Genet C Semin Med Genet, 2011, 157C(2):129-135. https://doi.org/10.1002/ajmg c.30295 PMID: 21495173 PMCID: PMC3086095

[20] Siegel DH, McKenzie J, Frieden IJ, Rauen KA. Dermatological findings in 61 mutation-positive individuals with cardiofaciocutaneous syndrome. Br J Dermatol, 2011, 164(3):521-529. https://doi.org/10.1111/j.1365-2133.2010.10122.x PMID: 21062266 PMCID: PMC4063552
[21] Cesarini L, Alfieri P, Pantaleoni F, Vasta I, Cerutti M, Petrangeli V, Mariotti P, Leoni C, Ricci D, Vicari S, Selicorni A, Tartaglia M, Mercuri E, Zampino G. Cognitive profile of disorders associated with dysregulation of the RAS/MAPK signaling cascade. Am J Med Genet A, 2009, 149A(2):140146. https://doi.org/10.1002/ajmg.a.32488 PMID: 19133693

\section{Corresponding authors}

Alexandru Daniel Jurcă, Lecturer, MD, PhD, Department of Preclinical Disciplines, Faculty of Medicine and Pharmacy, University of Oradea, 101 December Square, 410068 Oradea, Bihor County, Romania; Phone +40744-392 802, e-mail: alexjurca@yahoo.co.uk

Codruţa Diana Petcheşi, Assistant Professor, MD, PhD Student, Department of Preclinical Disciplines, Faculty of Medicine and Pharmacy, University of Oradea, 101 December Square, 410068 Oradea, Bihor County, Romania; Phone +40742-093 604, e-mail: petchesi_diana@yahoo.com

Received: May 23, 2021

Accepted: December 21, 2021 